\title{
LA CASA DE BERNAT DE SARRIÀ, CANONGE DE LA SEU DE BARCELONA, VERS 1300
}

\author{
CARME BATlle I GallarT \\ Universitat de Barcelona
}

\section{SUMARI}

I. El canonge Bernat de Sarrià.- II. La casa d'un ric canonge: 1. La cambra. 2. El menjador-sala. 3. La cuina. 4. La planta baixa.

Les cases de famílies benestants de Barcelona, que podem conèixer per mitjà dels inventaris, han atret la nostra atenció des de fa temps. Conegudes les dels rics ciutadans i drapers del segle XIII', ara presentem la d'un canonge de la Seu anomenat Bernat de Sarrià. Tot i que no tenim notícies exactes sobre la família del canonge, deduïm de les escasses dades personals contingudes en el seus testament $i$ inventari, la seva pertinença a l'antic llinatge dels Sarrià. Es tracta dels posseïdors de la casa forta de Sarrià, que es trobava en el territori de Barcelona, a la vila o parròquia de Sant Vicenç de Sarrià, nascuda al seu voltant. Sembla que fou bastida durant la fortificació del Pla de Barcelona desprès dels atacs d'Al-Mansur i del seu fill. Pertanyent a la Canonja per cessió del comte de Barcelona el 1040, la

\footnotetext{
'Amb el meu agraïment a Elena Cantarell per la seva collaboració. Carme BATLLE I GALLART, La familia i la casa d'un draper de Barcelona, Burget de Banyeres (primera meitat del segle XIII), "Acta /Mediaevalia”, 2 (1981), pp. 69-91. ID., La casa $i$ els béns de Bernat Durfort, ciutadà de Barcelona, a la fi del segle XIII, "Acta/Mediaevalia", 9 (1988), pp. 9-51. ID. La familia i els béns de Pere Marí. escrivà de la reina Constança vers I300. "Acta/Mediaevalia”. 14-15 (1993-1994), pp. 243-258.

"Anuario de Istudios Medievales". 28 (1998)
} 
torre fou ampliada amb una fortalesa i fou infeudada a un personatge, Pere Joan, que prenguè el nom del lloc. Potser procedia de l'entorn de l'abat del monestir de Sant Cugat del Vallès, ja que el seu fill, el cavaller Guillem Pere, en el seu testament de l'any 1148 manifestava que tenia el càrrec de "batlle de sach" dels vassalls del monestir a Sarrià. El vincle no es trencà perquè un nebot o renebot seu, Bertran, fou monjo de l'esmentat monestir.

Al mateix temps observem la tendència del llinatge a destinar un dels fills a la Seu de Barcelona; és el cas de Ramon, un germà del monjo que arribà a ser canonge, i de Bernat, fill de l'al-ludit Guillem Pere, que en el seu testament li deixava unes terres a fi que fos clergue i canonge (ja ho era el 1202$)^{2}$. Un altre vincle que unia els Sarrià a l'Esglèsia, és el patronatge, sistema normal de relació entre nobles i eclesiàstics que necessitaven ajut $\mathrm{i}$ protecció durant la seva carrera. En efecte, entre els protectors laics hi trobem els Sarrià, ja que alguns membres d'aquest llinatge patrocinaren la carrera de diversos joves de la vila ${ }^{3}$.

Els dos canonges Sarrià són els precedents familiars del canonge Bernat de la segona meitat del segle XIII, germà del cavaller Romeu, que devia ser l'hereu de la casa forta (citat a les notes 3 i 9) i contemporani del personatge més important del llinatge, el seu cosí del mateix nom. Ens referim al cavaller Bernat de Sarrià, un dels protagonistes de la vida política catalana dels volts del 1300 , conseller de diversos monarques, sobretot de Jaume II, que l'apreciava molt, l'ennoblí i el recompensà bé pels seus continuats serveis com a tresorer, almirall, ambaixador, amb la concessió d'un extens domini al sud de València. Mitjançant les cròniques, sobretot la de Ramon Muntaner, que fou procurador seu, coneixem la carrera militar i

2F. Carreras Candi, Notas históricas de Sarriá. Barcelona, 1897, pp. 97-104, apèndix documental núms. VI, XII, XIV; F. DE SAGARRA I DE SISCAR, Sant Vicens de Sarrià. Dades i clarícies referents a la història d'aquesta vila i parròquia, Barcelona, 1921, cap. IV; a la pàg. 64 consta que l'11-IV-1189, Berenguer de Sarrià del Palau i els seus tres fills atorgaren donació del seu fill i germà Ramon a l'esglèsia de Barcelona perquè en fos clergue i canonge; a la pàg. 103 hi ha l'exemple de 1202. Josep BAuCELLS I REIG, L'entorn familiar de Ponç de Gualba, bisbe de Barcelona (1303-1334), "Homenatge a la Memòria del Prof. Dr. Emilio Sáez. Aplec d'Estudis dels seus deixebles i col-laboradors", Barcelona, 1989, pp. 445-460. Pere ORTi I Gost, La casa i les possessions d'un jurista barceloní segons el seu inventari de béns: Burget de Sarrià (1338), "Miscel-lània de Textos Medievals", 7 (Barcelona, 1994), pp. 323-369. Burget no sembla formar part de la familia noble, però hi estava relacionat.

${ }^{3}$ Arxiu de la Catedral de Barcelona (ACB), pergs. 1-6-2485 del 24-II-1252; 1-6-1311 del 20-XII-1254 i 1-6-1121 del 17-XII-1253. El cavaller Bernat es comprometé a protegir Bernat Magraner, acòlit del bisbe barceloní R. de Centelles, i a Bernat de Corts, de Sarrià; el cavaller Romeu féu el mateix amb G. Ferrer també de la vila. 
política del cavaller Bernat iniciada com a donzell juntament amb el seu germà Vidal -el nom del pare- a Alcoll quan Pere el Gran preparava la conquesta de Sicília ${ }^{4}$.

La seva categoria social, assolida pels bons serveis fets a la monarquia, es manifesta en l'ambiciosa política matrimonial portada a terme pel seu propi enllaç amb Isabel de Cabrera, pertanyent a una família noble superior als Sarrià. Encara més ambiciós és el projecte de matrimoni del seu hereu Vidal, amb una filla natural del rei Frederic III de Sicilia ${ }^{5}$. Naturalment en l'ambient familiar el prestigi del noble Bernat és innegable, com ho demostren les dues referències fetes pel canonge Bernat en el seu testament, com veurem, i també el fet que un altre cosí, igualment anomenat Bernat, senyor de la casa de Sarrià, confiés al poderós cavaller dos dels seus nombrosos fills: el noi Guillem i la nena Saurineta, amb el desig que rebessin al seu costat una bona formació i després un destí; el cosí s'havia de preocupar de casar la nena ja dotada amb la suma de 12.000 sous pel seu pare ${ }^{6}$. Aquest personatge, sens dubte el més significatiu de la nissaga, va morir el 1335 essent alcaid del castell de Xàtiva?

\section{El canonge Bernat de SARrià}

El canonge Bernat es recorda dos cops del seu prestigiós cosí homònim en el testament ${ }^{8}$, al mig $\mathrm{i}$ cap al final anomenant-lo primer conseller del senyor rei i després "estimadissim consanguini”, sempre per

${ }^{4}$ Les quatre grans cròniques, ed. F. Soldevila, Barcelona. 1971, sobretot les pp. 99, 111, 476, 634, 806. F. CARRERAS CANDI, op. cit. . pp. 135-151, aporta documentaciò d'ACA sobre el personatge.

${ }^{5}$ El 22-1II-1309. el noble Bernat, almirall i conseller del rei d'Aragó i el seu fill nomenàren procurador seu a Jaume de Belltall, cavaller, per tractar l'esmentat enllaç "per verba de presenti". es precisa; a més, podrá negociar les sumes del dot, de l'esponsalici i de l'augment, i també obligar per aquest motiu els castells alou dels Sarrià a València, per exemple el de Polop. El procurador podrà aprofitar el viatge a Sicilia per cobrar una suma deguda a Bernat (ACB Bernat de Vilarrúbia, man 9 (1308-1309), ff. 219-220 v.).

${ }^{6}$ Testament de Bernat de Sarrià, casat amb Saura de Torrelles, del 3-V-1328 (ACB, B. de Vilarrúbia, man.42, 1300-1332, ff. 67 v.-70).

${ }^{7}$ Crònica de Pere el Cerimoniós, op. cit.. pp. 1023 i 1171 sobre la mort de Bernat de Sarrià i la seva fidelitat al rei Pere contra la reina Elionor.

${ }^{8}$ ACB PA 4-3-152, 29-XII-1300. Testament característic d'un canonge -ho són també tres dels seus quatre marmessors- per les fundacions i deixes. Els testimonis són tres clergues, dos manescals, segurament germans, i un home sense definir. La caplletra ocupa sis línies. 
demanar-li favors. D'antuvi li encomana Guillemó, fill de Ramon de Vilanova cavaller d'Osona, que pertanyia a casa seva i al qual deixa un rossí valorat entre 100 i 130 sous i sella i fre que li han de comprar els marmessors, potser per esdevenir cavaller com son pare; li demana que el rebi a casa seva i el protegeixi. El segon encàrrec encara demostra més l'extraordinari grau de confiança existent entre els dos cosins, ja que no solament li demana consell i ajuda pels marmessors quan li sol-licitin, sinó que li prega que completi amb diners propis la suma destinada pel testador en cas que no fos suficient per fer efectives totes les deixes estipulades, detall que evidencia una gran preocupació per la salvació de la seva ànima, que era la finalitat de totes les despeses.

El canonge no oblida tres monges que devien ser parentes seves: Saurina de Sarrià, del monestir de Valldonzella, Arsenda de Bellveí, de Sant Pere de les Puel-les, i Elvira de Bellveí, sots-priora de Jonqueres, a cadascuna de les quals deixa 50 sous per vestits i altres coses necessàries. També es preocupa de la gent que convivia amb ell o sia la família: l'esmentat Guillemó de Vilanova, el fill de Bernat Porcell de la vila de Caldes de Montbui, que encomana al canonge Jaume d'Olorda per tenir-lo a casa i protegir-lo; Berenguer de Banyeres, al qual destina 100 sous abans de confiar-lo al bisbe electe Ponç de Gualba (bisbe de Barcelona de 1303 a 1334) perquè el rebi entre el seus familiars - potser per ser clergue-; i per fi, la seva fillola Caterina, que s'ha de beneficiar de la porció de pobre fundada pel testador, com veurem. En darrer lloc, Pere de Puigalt, que era el clergue de casa seva, és recompensat amb la fundació presbiteral del testador. Totes aquestes fundacions i deixes foren una realitat gràcies a la fortuna del canonge basada en propietats agrícoles. La majoria anaren a mans de l'Almoina per la porció del pobre i eren les situades a Premià: el más Cisa $\mathrm{i}$ altres terres adquirides per ell a Berenguera de Vilallonga per l'elevada quantitat de 4.050 sous de Barcelona el 17 de setembre de 1295; a més, tenia també unes propietats a Alella". A més d'aquestes propietats,

'J. BauCElls I ReIG, El Maresme i la Pia Almoina de la Seu de Barcelona: imentari dels pergamins, Barcelona, 1987, p. 106, docs. 262-264 i 295, on consta Romeu de Sarrià germà del canonge. N. JASPERT, El patrimoni dels canonges regulars a la Barcelona medieval, "III Congrés d'Història de Barcelona. La ciutat i el seu territori, dos mil anys d'histơria", Barcelona, 1993. 
cobrava les rendes procedents de la capellania de l'església de Santa Maria de Caldes de Montbui, perquè ell era el capellà de la dita església ${ }^{10}$.

Amb aquest objectiu pietós manà vendre tots els béns que no fossin diners en metàl-lic, i reunir totes aquestes quantitats amb les seves rendes $i$ els deutes recobrats per pagar les deixes testamentàries i desprès destinar la resta a comprar rendes alodials en llocs idonis a fi d'obtenir de la inversió de 30 morabatins censuals els interessos suficients per mantenir un sacerdot, Puigalt de moment, com a rector de l'altar de Santa Cecília, situat a la capella de Sant Miquel - al costat de la sala capitular de la catedral- i fundat pel canonge Bernat per celebrar perpètuament el seu aniversari" ${ }^{\prime \prime}$

Bernat participà del moviment a favor dels pobres, que aleshores es vivia a la Seu de Barcelona, amb la fundació d'una porció de menjar per un pobre en el refector canonical; per tant consta amb el $n^{0} 53$ en la relació de fundadors de l'Almoina de la catedral que inclou 155 noms $^{12}$.

De tota manera decidí que la porció o una de les porcions, si les rendes permetien que fossin més d'una, fos per a Caterina, la seva fillola $i$ resident a la mateixa casa, mentre visqués (potser perquè no era ben normal).

És evident que la seva vinculació a la catedral va ser molt forta fins al darrer moment, perquè hi desenvolupà tota la seva vida. Aquí actuava normalment amb els seus companys durant les reunions de la canònica almenys des de l'any $1266^{13}$. En diverses ocasions estampà la seva signatura en documents, per exemple el 1271 quan ho féu per ell mateix i pel sagristà, del qual era procurador, entre els altres canonges, en l'acta de

\footnotetext{
${ }^{10}$ El 25 de maig de 1295, el canonge reconeixia hever cobrat les rendes, sense indicar-ne la suma concreta, a Guillem d'Alda, clergue, i a Arnau d'Alda, jurisperit, germà seu, als quals havia venut les rendes (ACB. notari Bernat de Vilarrúbia, manual 2 de 1295, fol. 51 v.

"A més havia de celebrar altres aniversaris: pels difunts R.de Sau, rector de l'esglèsia de Granollers, i P.de Truyols, dels quals Bernat era marmessor, per B. d'Olorda, canonge de la Seu barcelonina, i Agneta o sia Agnès Grony, mare de B. de Centelles, senyor del castell del Far, si aquest darrer ho permetia. El canonge era l'administrador de tots els esmentats aniversaris que. a la seva mort. passaren a ser-ho pel rector de l'altar de Santa Cecília.

12J. Baucells, La Pia Almoina de la Seu de Barcelona, "A pobreza e a assistência aos pobres na Península Ibérica durante a Idade Média”, 1, Lisboa, 1973, p. 124. Bernat seguí els passos del seu parent R.P. de Sarrià, jutge, que el 1263 institui diverses racions per a pobres el dia del seu aniversari (J. BauCELLS, Gènesi de la Pia Almoina de la Sel de Barcelona: el. fundadors. "La pobreza y la asistencia a los pobres en la Cataluña medieval", Barcelona, CSIC, 1980, pp. 25, 42).

${ }^{1: A C B}$ Index de Caresmar. vol.1 (2)
} 
fundació de tres presbiterats pel bisbe Arnau de Gualba ${ }^{14}$; per tant es conserva la seva signatura autògrafa en documents de l'Arxiu de la Catedral de Barcelona. Durant anys hi tingué el càrrec de prepòsit del mes d'abril ${ }^{15}$, i com a tal administrava nombroses propietats, entre elles una situada a Montjuic a la vora del cementiri dels jueus; per raó d'aquesta finca havia dipositat unes penyores (set escudelles d'argent $\mathrm{i}$ una cinta de seda grisa guarnida d'argent) en poder del canonge barceloní Eimeric Bou i d'Arnau de Sarrià, canviador, a causa d'unes sumes (dites) relacionades amb un problema existent entre ell i els secretaris del Call jueu per l'esmentada propietat.

Els marmessors del canonge també tenien la mateixa dignitat (mestre Arnau de Torre, Humbert Dezllor i Guillem Tarafa), exceptat Bernat d'Horts, clergue rector de la capella de la casa dels malalts de Barcelona; s'havien d'encarregar de pagar els seus deutes, com era costum, i de preocupar-se de la seva sepultura a la capella de Sant Miquel, on havia fet construir i havia dotat l'altar de Santa Cecilia, ja esmentat ${ }^{16}$. Com que era un home molt meticulós, el testador precisava que volia ser enterrat al costat esquerre de l'altar, on hi havia un banc, que l'enterrament s'havia de fer bé i honorablement, segons el costum de la Seu. Especificava les deixes habituals: el seu llit de draps a l'hospital de la catedral o d'En Colom, 5 sous a cada hospital de pobres de la ciutat (de Bernat Marcús, Pere Dezvilar, Santa Eulàlia del Camp) i a la Casa dels malalts, un àpat pels franciscans i un altre pels frares predicadors dels convents de la ciutat, perquè preguessin per la seva ànima, i per fi destinava 100 sous per l'obra de la Seu tot just començada feia un parell d'anys.

En conjunt, repartia tota la seva fortuna, que és impossible avaluar, entre fundacions i deixes pietoses amb una única finalitat, la salvació de la seva ànima. La resta del béns, si encara quedava alguna cosa desprès d'aquest repartiment, havia de ser pels seus hereus universals: Déu, els seus pobres i causes pietoses, amb el mateix objectiu, encara que no consti

\footnotetext{
${ }^{14}$ S. PuIg I PuIG, Episcopologio de la Sede Barcinonense, Barcelona, 1929, p. 455, on consta la seva signatura autògrafa.

${ }^{15}$ El càrrec i el problema consten a l'inventari per indicació dels servents del canonge que ho comuniquen als marmessors (línies 43 i 44).

${ }^{16}$ Línies 21 i 26 de l'inventari: consten objectes que eren a casa del canonge però que estaven destinats a aquest altar, com una cortina, un missal complet que havia comprat amb aquesta finalitat, un calze d'argent daurat de dins i de fora, amb la seva patena també daurada de dins $i$ de fora.
} 
explícitament. Per tant, es comprèn l'interès del canonge per evitar una possible manca de diners per pagar-ho tot $\mathrm{i}$, en aquest cas, la seva petició d'ajut econòmic al seu poderós cosí. Si bé la seva fortuna sembla considerable i consistia en propietats, que no consten en el testament -sí els documents de la seva adquisició a l'inventari-, la seva preocupació es manifesta en la petició al cosí i al tracte donat als seus esclaus, obligats a comprar la seva llibertat a un preu molt alt.

Tenia tres esclaus, un d'ells ja batejat anomenat Pere Guerau, que podia quedar lliure si dins de l'any de la mort del seu amo pagava als marmessors 150 sous; la mateixa condició posà a l'esclava Alamanda. Si no pagaven els diners que el canonge destinava a les seves deixes testamentàries, els marmessors els vendrien per obtenir les sumes. Com consta a l'inventari dels béns, l'esclau fugí. Com que el canonge els considerava part del seu patrimoni, el seu projecte d'alliberament és molt relatiu, només és una intenció condicionada per la qüestió econòmica malgrat ser batejats, i que fracassa en el cas de l'esclau. No ens sorprén, perquè la suma exigida és molt elevada per aconseguir-la en un any en qualsevol treball ${ }^{17}$. Es pot remarcar la igualtat de condicions d'alliberament dels dos esclaus, sense diferència per rạó de sexe, potser perquè les esclaves tenien la possibilitat de guanyar diners exercint la prostitució; molts les compraven per fer aquest negoci.

A més d'aquests dos, tenia un altre esclau batejat i negre, anomenat Jaume, que no s'esmenta en el testament, però sí a l'inventari. El devia adquirir desprès de dictar les seves darreres voluntats el 29 de desembre del 1300 , ja que va viure encara un temps, com demostra la data de l'inventari, fet el 26 de juliol de $1302^{18}$.

\section{LA CASA D'UN RIC CANONGE}

A la mort del canonge Bernat, enterrat el dia 25 de juliol de 1302 , es realitzà immediatament l'inventari dels seus béns datat de l'endemà del

\footnotetext{
${ }^{17}$ Podem comparar la xifra amb el sou de l'administrador de la Casa dels malalts a la mateixa data, $100 \mathrm{~s}$. anuals, mentre que els "servents dels malalts" o leprosos en cobraven de 65 a 80 (A. Pérez Santamaria, El hospital de S. Lázaro o casa dels Malalts o Masells, "La pobreza y la asistencia” p. 104)

${ }^{18}$ ACB PA 4-3-152 a, escrit pel notari Bernat de Vilarrúbia, com també el testament.
} 
sepeli, detall que demostra l'interès per controlar-ho tot. Es féu a instància dels marmessors, que són els mateixos nomenats en el testament, però el darrer, un clergue, no consta com a rector de la capella de la Casa dels leprosos, potser per oblit del notari o perquè ja no exercia el càrrec. Tots quatre aprovaren l'inventari i el signaren davant del notari autor dels dos documents i de sis testimonis, eñ primer dels quals és Bernat de Sarrià, fill del difunt cavaller Romeu, és a dir un nebot del canonge Bernat; segueixen un altre parent, Bernardó de Sarrià,senyor de la casa de Vallverd, i quatre preveres: Nicolau de Verdeguer, Pere de Manresa, Pere de Puigalt, ja esmentat en el testament, i Guillem d'Arbúcies. A l'inventari no es concreta la situació del domicili del canonge, que devia trobar-se vora la catedral, com era costum, ni la distribució de la casa, en la qual només es pot identificar amb seguretat el celler, la cuina, l'estable, el graner, una sitja i el pati posterior, si ho indica el notari o segons els atuells descrits. Tot i que el desordre, des del punt de vista actual, no permet afirmar res en concret, pensem que el notari seguí una ordenació espacial per fer la descripció dels béns mobles cambra per cambra i per tant establim la cambra principal on s'esmenta el millor llit, i el menjador-sala on es descriuen uns armaris penjats a la paret, taules i bancs; segurament es tracta d'una sala amb alcova.

Tampoc aquí no s'enumeren les propietats del difunt, ja que només s'esmenten en general uns documents de compra d'honors o finques guardats en una caixa de fusta i juntament amb altres escrits posats en un sac que fou segellat amb el segell del canonge Tarafa, un dels marmessors. A més, uns altres documents es troben en una "candelaria" petita amb uns trocets de fusta que podrien ser d'àloe (quedam frustra ligni que videbantur esse linyoloe). Tot era a la cambra del difunt, com també uns documents trobats al costat dels diners.

\section{La cambra}

Pensem que es comença l'inventari a la cambra principal ${ }^{19}$, on hi ha el bó i millor de la casa, els documents i els objectes més valuosos, al costat de la roba del canonge. El seu llit, ben parat i endosserat amb una alquella, és descrit com "tornadís amb cordes i escó"; a continuació consten una màrfega, un matalàs de "metxí", un travesser amb plomes, una

\footnotetext{
${ }^{19}$ Són les linies 4 a 18 de l'inventari.
} 
"vaneta", tres matalassos i un cobertor de burd, a més de dos matalassos sarraïns de cuir vermell vells, que fan suposar un llit molt alt i que algun servent dormia a la cambra de l'amo. El capellà de la casa podia dormir sobre una màrfega esmentada més avall, amb travesser de plomes, mentre que els servents ho farien sobre els bancs situats a la vora o a dins de la cuina $\mathrm{i}$ els esclaus viurien a la planta baixa, ja que són inventariats a l'estable.

Destaquem els objectes valuosos: set culleres d'argent i un cullerot de cristall en una caixeta amb dos parells de guants de cuir, dues corretges per aus de caça (gits) i menuderies (minuta); una corretja de "camut" amb el cap, la mosqueta o agulla i platons d'argent amb la bossa de seda. Dins d' una caixa gran amb peus hi havia catorze copes d'or i d'argent daurat, una tassa d'argent i un pom granat daurat i buit.

Quant a les copes es fa la distinció entre "cupa" i "cifus" en la següent descripció:

1.- una copa amb el seu copó que es considerat tot un conjunt d'or, ambdós amb senyal d'estrella a l'interior i decorats amb esmalts de colors verds, blancs i lívids;

2.- una copa amb el seu copó, daurats a l'interior,

3.- un gran "cifus" d'argent daurat de dins i de fora, amb el signe d'arbre a l'interior,

4.- un "cifus" fet de fusta de noguera amb el peu d'argent,

5.- un altre d'argent, en part daurat de dins i de fora, l'interior,

6, 7.- dos més d'argent daurats de dins, un amb una creu al mig a

8.- un altre d'argent daurat de dins i de fora, amb un esmalt a dins,

9.- un altre d'argent daurat de dins i de fora, amb un esmalt a dins, al mig, en forma de quimera,

10.- un altre d'argent, daurat de dins,

11.- un altre d'argent amb un esmalt al mig amb un escut de barres,

12.- un altre daurat de dins, amb un esmalt dins, al mig, en forma de quimera,

13.- un altre de petit amb mig peu daurat $\mathrm{i}$ un esmalt al mig,

14.- un altre d'argent daurat de dins, amb el seu estoig de cuir.

També tenia coses de seda: un coixí i cinc tovalloles obrades de seda, dues bosses forrades de cuir, dos parells de lligacames i dues lligacames de seda i fil de llí (trabugaria, trabugias), dues benes obrades de seda i dues més utilitzades per fer un torniquet en sagnar; altres robes de 
seda es troben al menjador. Aquí encara s'esmenten estovalles de taula, unes catalanes i altres franceses, i una gingebrada o salsa de gingebre "contaminada".

Les úniques joies que tenia el canonge eren anells, deu guardats en dues caixetes: dins la primera de cuir negre un anell gros d'or amb una pedra vermella envoltada de pedretes verdes que també encerclaven tot l'anell, sis anells d'or lligats amb una cordeta de seda (un amb una pedra llarga verda, un amb una de grossa vermella, dos amb safirs blancs, un amb una pedreta verda, un altre també amb pedra verda encerclada amb quatre pedretes verdes); dins la segona, de cuir de colors i obra d'estany, hi havia tres anells, un d'or amb una pedra de colors, un d'argent amb una pedra en forma d'escut, un d'or amb una pedra grisa i fosca. Altres objectes valuosos són cinc pintes d'ivori, un ganivet amb el mánec de corall, i també monedes: 1.171 sous en diners de Barcelona d'argent $i$ un tornés d'argent.

Encara hi havia uns document definits com instruments de forma pública, que ja hem situat abans amb els altres.

Quant a les robes trobem un vel blanc amb el voraviu vermell, dos vels llargs de fil un amb el voraviu negre i l'altre gris, roba a punt per fer-se fer un parell de calces de drap negre, roba de llí de 4 a 6 canes, i una camisa de fil. Cal esmentar també un parell de guants de cuir, un pectoral de sella geneta i tres cinyells de llana ratllats pels cavalls, un tinter i un saler de fusta, una barreta i dos ganivets junts en una beina; també una corda pel capell de sol que es troba en un altre àmbit, la sala, juntament amb els vestits del canonge.

\section{El menjador-sala}

A continuació de la cambra el notari canvia d'espai per passar al menjador-sala ${ }^{20}$, de grans dimensions per encabir el gran nombre de mobles inventariats. També podria tractar-se del menjador compartit pel canonge $\mathrm{i}$ la seva "familia", els homes esmentats en el testament, i d'una cuina propera, on cuinaven i menjaven els servents que sovint son citats com informadors dels marmessors durant la confecció de l'inventari. De fet, en un primer àmbit hi havia taules de fusta, tres planes $\mathrm{i}$ una amb els peus plegables, dos bancs llargs i una banca, cinc estores de jonc primes.

\footnotetext{
${ }^{20}$ Línies 18 a 32 .
} 
Dels dos armaris penjats a la paret no se'n detalla el contingut, però a continuació s'enumeren dos ventalls pintats amb senyal de bastó (caye), robes per encortinar, un drap llarg barrat de verd i d'altres colors, un altre també llarg barrat de vermell i d'altres colors, un barragà vell (roba gruixuda de llana) i un altre amb ratlles blanques i vermelles, dos cobertors (un de "scindone", potser setí, vermell, i un de burd), dues vànoves grans blanques i primes, dos tapets (un de bo i un de vell), una cortina petita obrada de diversos colors, un exaló vermell tenyit de grana i un de groc ratllat, $i$ per fi dos càntirs o flascons grans de coure estanyat $i$ un altre trencat. També hi ha un vestit senzill de frare (carpita pilosa).

Dins un dels armaris hi devia haver el vestuari del canonge juntament amb una peça de roba de 5 canes i mitja de color mixt tenyida de grana. Tenia tres mantells de pell de bé, una gramalla de drap de color de foc amb "scindone" vermell (segurament setí pel folre) i caperó de conjunt, una altra gramalla de drap lívid de pells d'alfanets (poden ser plomes de falcons com consta en el Diccionari Moll?) i el caperó igual, folrat de "scindone" vermell; una tercera gramalla era d'exaló lívid, gairabé nova, amb caperó. Seguien una capa curta de drap morat de mitja seda amb pells de conills blanques, un salvacors (com una armilla) de drap groc amb pells de conill negres, una túnica de drap blanc, una cota vella de camellí amb pells velles de conill negres i caperó del mateix drap amb pells de vaires (una mena d'esquirols o potser gats salvatges), una túnica de drap verd amb dos parells de mànegues i per fi un capell de sol amb "scindone" vermell (segurament en el folre) i un carner de cuir vermell, dos objectes que servien durant els viatges.

Aquí, com abans a la cambra, hi ha roba de casa: tovalloles, coixins (un de petit és obrat "cum scripturis de cirico"), llençols, cinc estovalles, sis tovallons. Els mobles són seients (setis), dos de llargs, dos escambells de cuir (recubitorium). Trobem una maça de ferro, que és l'única arma inventariada, dos bacins de coure per servir, un de llautó pel barber vora dues "trocerias" de cuir, un llibre de pergamí anomenat "Processional", un Breviari, un escriptori, tot ben necessari per un canonge. Dues braceroles o peces de l'arnès porten l'emblema heráldic del difunt o senyal, que podem identificar amb una petxina ${ }^{21}$, unes regnes de cuir, un parell de tapins (no

\footnotetext{
${ }^{21}$ L escut de la família Sarrià porta diverses petxines de pelegrí, 3, 5 o 7, d'argent sobre fons de color i encara es recorda en l'escut municipal de Sarrià que té una petxina al centre (CARreras CandI, op. cit, pp. 112-113; Sagarra, op. cit. pp. 70-80 i lám. inicial.
} 
consta cap més calçat), un carner petit. Els següents objectes pertanyen al menjador, però no consta l'escudeller on es solien posar: onze escudelles d'estany bones i una trencada, nou discos o plats, tres platells i cinc graelles d'estany, ampolles i copes de vidre, un ventall rodó de plomes de paó, etc.

En aquest punt comença una enumeració de caire diferent que manifesta un canvi. Podria ser un altre menjador o una part de la mateixa sala $^{22}$, més conectada amb la cuina, que és l'espai següẻnt. El mobiliari consisteix en una caixa de fusta amb cinc ròtols d'espelmes de cera blanca (potser també hi són els objectes descrits a continuació: quatre coltells de taula en una beina, un altre amb el mànec mig de corall i mig de la pedra dita jaspi amb la beina, un manil, una setra de llautó), una taula, un banc i dos seients llargs, una màrfega i un travesser de plomes, una càtedra de fusta i una taula petita de peus plegables (potser tot destinat al canonge que presidia la sala), una mesa llarga amb peus plegables, cinc meses llargues amb peus, tres bancs, una arca, un taüt petit i vell, una bòta petita, una taula plana semblant a un banc, un banc llarg, tres "legenas" o mesures de líquids, dues estores velles, un tauler de taules per jugar.

En mig de tot això o dins de l'arca hi ha un foguer petit i rodó de ferro (fogerium), al costat d'un escriptori, un breviari, un cavallfust per una sella i una caixeta vella amb escrits a dins.

\section{La cuina}

Sense cap indicació per part del notari sembla que la següent enumeració d'atuells correspon a la cuina ${ }^{23}$. Ens hi introdueixen una gerra d'oli, tres mossos de frens de cavall, quatre frens i dos bancs de frens. Pertanyen ben bé a la cuina una conca i una perola amb nanses, ambdues de coure, també ho és un morter amb la seva mà, un de marbre, dues graelles de ferro, una setra de llautó i una d'estany, dues gerres de terra buides, un taüt vell amb farina (consten pocs aliments a la cuina i al celler), un altre sense coberta, una nansa de joncs potser pel peix, dos ferros per cuinar, dos clemàstecs de ferro - un de gran i un de petit-, una cassa i una caldera de coure i una coberta de ferro, dues paelles - una trencada-, una giradora $\mathrm{i}$ dues lloces de ferro, un poal de coure, una quantitat de discos i d'escudelles

\footnotetext{
"2Linies 27-32.

${ }^{23}$ Línies 32 a 35
} 
de fusta, segurament destinats al servei per ser de menys qualitat que els d'estany inventariats al menjador. A més, hi havia cinc selles: una nova amb l'emblema del difunt, una "geneta", dues de velles - una amb el senyal del difunt - i una encuirada, i dues vergues de ferro. El mobiliari consistia en dues taules planes i dos bancs: una taula i un banc consten primer i els altres dos més endavant, com si es trobessin ben separats.

\section{La planta baixa}

Aquí sembla l'inici d'un altre dia en la redacció de l'inventari o almenys el notari comença un nou apartat introduit per mitjà de la frase: "Item invenimus in dicta hereditate...", perquè el notari s'ha traslladat baixant l'escala cap a la planta baixa ${ }^{2+}$. En el primer espai que dòna pas cap al pati posterior ("retrocurtale"), hi troba tres cups grans i tres de petits, una tona buida i una escala de fusta. En el mateix pati hi ha llenya per cremar a la cuina ("quinque saumate et quatuor paria et medium ancerum").

A continuació es repeteix la frase introductòria esmentada abans per donar entrada a l'estable, on hi ha una mula de pèl beig clar, una altra de pèl beig amb pèls bruns i un rossí o cavall de poca categoria; recordem les selles, frens i altres objectes relacionats amb les cavalleries guardats a la sala o vora la cuina pel seu valor. Amb aquests animals hi conviuen tres esclaus batejats: el negre Jaume, Alamanda i Pere Guerau. El canonge oferí als dos darrers la possibilitat de comprar la seva llibertat, com consta en el seu testament, però l'home fugí davant la impossibilitat de reunir els 150 sous exigits en el termini d'un any.

A la vora de l'estable hi ha el celler, ben proveït amb una tona gran buida, tres bótes grans plenes de vi - en una d'elles el vi tenia tres anysi tres buides, dues bótes mitjanes plenes, una de petita plena i una de buida, un ambut de les botes $i$ un de les ampolles, un quarter de coure, tres parells i mig de portadores, una quartera de fusta de mesura de Barcelona i una altra de mesura de Granollers, dues mesures rodones de fusta, dues cordes de cànem i una xàvega - xarxa per transportar palla, per exemple- de "tranyelles" d'espart. El vi devia ser de la collita de les propietats del canonge a Premià, com també l'ordi amagatzemat al graner, 8 quarteres, $\mathrm{i}$ en una sitja, 70 quarteres més i encara no era ben plena, segons informaren

\footnotetext{
${ }^{24}$ Línies 35 a 42
} 
els domèstics o servents del canonge, i encara mancava rebre uns censos de blat. També hi havia tres bótes mitjanes plenes de vi i una de buida, sis culleres d'argent (és sorprenent en aquest lloc!), una aixada, una destral i una ratera de ferro. Per fí trobem tres capons vells i, segons la informació d'els servents, tres més que estaven en poder d'una dona anomenada $\mathrm{Na}$ Granera.

Tant el vi, com els grans, els capons i l'oli de la cuina procedien de les propietats del canonge situades a Premià i Alella, totes en mans de pagesos que li pagaven censos en especie mesurats amb la mesura de Granollers, ja que en tenía una d'aquest lloc a casa mateix. Si el celler i el graner estaven per sota de la seva capacitat, era per l'època, la fí del mes de juliol, quan encara mancava fer la collita del blat i també veremar. Un cop acabades les tasques agrícoles i completes les provisions de casa del canonge, aleshores ja tenia la manutenció assegurada per tot l'any següent, com succeia a totes les cases benestants de la ciutat $^{25}$.

Els servents del canonge també assabenten al notari sobre l'existència de pertinences del difunt en mans del jurispèrit Bernat Arbert: una capa (clamidem) de camellot vermell amb folre de "scindone" verd i un cot de les mateixes robes i colors; li havia tornat a Arbert per raó d'un pagament (dita), que havia fet juntament amb d'altres amb motiu de la qüestió entre Geralda de Vilaregut i un cirurgià que havia tingut cura del seu fill Jaume de Vilaregut.

Els mateixos servents informen al notari sobre les pertinences ja aludides més amunt, que el canonge havia dipositat per raó de la prepositura, i a més l'existència d'una escudella d'argent empenyorada a Pere de Girona, carnisser, per un deute de 70 sous, i d'una altra empenyorada a Arnau de Sarrià, canviador, per un deute de 80 sous més o menys, escudella propietat d'Elisenda, esposa del notari Jaume de Letenal i abans del draper Joan de Banyeres ${ }^{26}$; encara una copa d'argent del difunt es trobava en mans del notari Pere de Vilardebò. Per fi, el notari fa constar diverses peces d'arnesos que no eren del canonge, segons indicacions del servents: sis camisoles de ferro, un capmall i guants de malles de ferro propietat del noble Bernat de Sarrià, el poderós cosí del difunt, que potser vivia a casa seva durant les

\footnotetext{
${ }^{25}$ T. VINYOLES, El pressupost familiar d'una mestressa de casa barcelonina per l'any 1401. "La societat barcelonina a la Baixa Edat Mitjana", Annex d"Acta/Mediaevalia". Barcelona, 1983. pp.101- 112 .

${ }^{26} \mathrm{C}$. BATLLE, Burget de Banyeres, citat a la nota 1.
} 
seves estades a la capital; un asberg amb el seu aparell de malles de ferro era de Guillem de Sarrià, un altre parent.

Tant aquesta presència dels parents a casa del canonge com el seu record en el testament, tot fa entreveure uns estrets lligams familiars afavorits sens dubte per la bona situació econòmica del nostre biografiat. Sembla que la presència d'un canonge en una família de la petita noblesa era un factor aglutinant bastant apreciat. Aquest tradicional vincle dels Sarrià amb l'Església no s'estroncà amb la mort de Bernat, ja que el seu cosí del mateix nom, el senyor de la casa de Sarrià, disposà en el seu testament ${ }^{27}$ que la carrera eclesiàstica fos el destí d'un dels seus nombrosos fills, també anomenat Bernat, al qual atorgà 2.000 sous a tal fi.

\section{RÉSUMÉ}

Étude du testament et de l'inventaire des propriétés d'un riche chanoine, Bernat de Sarrià, appartenant à une famille de la petite noblesse des alentours de Barcelone, où se trouvait leur maison fortifiée. Un chevalier, cousin et avec le même nom du chanoine, était conseiller du roi et un grand personnage à la cour à cette époque.

L'inventaire, daté du lendemain de la mort du chanoine, le 26 juillet 1302, est très riche en robes, meubles, monnaies, mais pas du tout en livres ou armes. Le chanoine possède trois esclaves, en plus des servants, catorze coupes d'argent, plus ou moins décorées avec des émaux et des incisions, une douzaine d'anneaux, et aussi des propriétés foncières à Premià et à Alella, sur la côte nord de Barcelone, d'où il tire le blé, l'orge, le vin et l'huile gardés dans son grenier et son cellier.

Sa fortune est destinée à un bénefice en commémoration de l'anniversaire de la date de sa mort, fondé dans la chapelle de Saint Michel de la Cathédrale, et aux pauvres, surtout à la nourriture quotidienne et perpétuelle d'un pauvre dans la fondation pieuse de la catédrale appellée "l'Almoina". À ces deux institutions pieuses il offre aussi le prix de rachat ou de vente de deux de ses esclaves.

\section{SUMMARY}

This article studies the will and inventory of goods left by a rich canon, named Bernat of Sarrià, who belonged to a noble family from the surroundings of Barcelona, where his house was built. The canon had a cousin -also named Bernat-, who was a king's

\footnotetext{
${ }^{27}$ Document ja citat a la nota 6 . Un altre Sarrià canonge de la Seu de Barcelona fou Arbert documentat al 1342 (SAGARRA, op. cit. p. 76).
} 
counsellor and a very influencial person at the court. The inventory is dated the day after the canon was dead, on the 26th July 1302. It contains a large number of clothes, furniture and coins, but neither books nor weapons. The canon also possessed several servants and three slaves, fourteen decorated silver cups, twelve rings and some landed properties in Premià and Alella (villages not far from Barcelona), that produced crops of wheat, barley, wine and oil. A benefice in memory of the date of his death was constituted, with his fortune, at Saint Michael's chapel of Barcelona cathedral. This benefice was devoted to the poors and especially to nourish, for ever, a poor person who was dependent of the cathedral's Almoina. The canon destined for these two pious institutions the amount he obtained of selling his slaves. 